\title{
ESTUDO DA CORROSÃO NOS COMPONENTES METÁLICOS DOS ISOLADORES DE VIDRO DAS LINHAS DE TRANSMISSÃO DE ALTA TENSÃO
}

\author{
M. B. QUEIROZ ${ }^{1}$, E. O. VILAR ${ }^{2}$ e P. F. OLIVEIRA ${ }^{3}$ \\ ${ }^{1}$ Universidade Federal Rural do Semi-Árido, Campus Caraúbas \\ ${ }^{2}$ Universidade Federal de Campina Grande, Departamento de Engenharia Química \\ ${ }^{3}$ Universidade Federal Rural do Semi-Árido, Campus Caraúbas \\ E-mail para contato: marcelo.queiroz@ufersa.edu.br
}

\begin{abstract}
RESUMO - Isoladores são dispositivos de extrema importância para o funcionamento das linhas de transmissão de energia, pois além de responsáveis pelo isolamento elétrico e sustentação dos condutores, respondem pela confiabilidade do sistema. Porém, tais dispositivos encontram-se diretamente expostos às intempéries, podendo ocasionar o surgimento de processos corrosivos em suas partes metálicas representando gastos com manutenção das linhas e falhas na distribuição de energia elétrica. O presente trabalho tem como objetivos realizar um estudo da cinética de corrosão na parte metálica (campânula e pino) dos isoladores de vidros usados em linhas de transmissão de alta tensão. Para isto foram realizadas análises metalográficas e ensaio eletroquímico de polarização linear. Os resultados mostram que as ligas metálicas que compõem o isolador estudado não são atacadas corrosivamente com facilidade, devido a formação de camadas passivas durante sua vida útil, mostrando que estas possuem ainda uma boa resistência à corrosão e ainda sendo competitiva para construção de isoladores do ponto de vista custo/benefício.
\end{abstract}

\section{INTRODUÇÃO}

No Brasil, é comum a utilização de isoladores de vidro em linhas de transmissão acima de $230 \mathrm{kV}$, tendo em vista que estes componentes garantem boa confiabilidade ao sistema, são de baixo custo e fácil manutenção. Isoladores elétricos, são materiais que apresentam alta resistência ao fluxo de corrente elétrica. Estes componentes são empregados nas linhas de transmissão para realizar o isolamento elétrico dos cabos condutores de energia e dar sustentação mecânica aos mesmos. Podem ser dos tipos: vítreos, cerâmicos e poliméricos, sendo o vítreo, o mais utilizado atualmente no Brasil, especialmente em linhas de alta tensão.

Por ser um componente muito importante para garantir a confiabilidade do sistema, e apesar de representar um baixo custo, quando comparado ao custo total de uma linha de transmissão, é fundamental ter conhecimento sobre suas características, composições, vantagens e desvantagens, afim de que possam ser aplicados de modo a evitar falhas e reduzir os gastos da concessionária. Segundo os dados da Companhia Hidroelétrica do São Francisco, CHESF, cerca de $60 \%$ dos desligamentos em linhas de transmissão acima de $230 \mathrm{kV}$ devem-se à falhas nos 


\section{9 a 22 de outubro de 2014 \\ Florianópolis/SC}

isoladores, que podem ocorrer devido à ruptura do dielétrico, atos de vandalismo ou ao processo corrosivo na estrutura metálica do componente (YANAGUIZAWA e SHINOHARA, 2011).

De um modo geral, tanto os isoladores quanto os seus componentes devem apresentar superfícies lisas, uniformes e sem defeitos. O pino deve ser fabricado em aço forjado zincado. Na parte a ser cimentada dentro da campânula, é revestido com verniz especial para modificar o estado da sua superfície. Este processo aumenta a resistência aos esforços de compressão e cisalhamento do cimento quando o isolador é submetido à tração. A campânula deve ser fabricada em aço forjado ou ferro fundido maleável com tratamento térmico e cimentada ao corpo do isolante, de modo a evitar sua ruptura. Deve também ser isenta de trincas, juntas, contração, bolhas de ar, rebarbas ou quinas vivas. Quando fabricada em ferro zincado apresenta alta elasticidade e resistência mecânica, combinados com resistência à corrosão e fácil fabricação. O processo de zincagem tem a finalidade de obter uma camada de zinco para impedir o contato do ferro com o meio corrosivo (YANAGUIZAWA e SHINOHARA, 2011).

Devido a longa vida útil, os isoladores permanecem muito tempo expostos à intempéries como umidade, variações de temperatura, maresia, dentre outros fatores que ocasionam o acúmulo de poluentes e a corrosão.

Corrosão pode ser definida como a deterioração de um material, metálico ou não, causada por ações químicas ou eletroquímicas do meio ambiente aliada ou não a esforços mecânicos. As interações físico-químicas entre o material e o meio em que se encontra podem acarretar prejuízos como desgaste, variações químicas ou modificações estruturais, tornando-o inadequado para o uso (GENTIL, 2012).

No estudo de um processo corrosivo devem sempre ser consideradas as variáveis dependentes do material metálico, da forma, do emprego e do meio corrosivo. Somente o estudo conjunto destas variáveis permitirá indicar o material mais adequado para determinado meio corrosivo. Sendo assim, é de fundamental importância o conhecimento do material utilizado nos isoladores para a realização de ensaios de corrosão, a fim de que se possa controlar o processo corrosivo nas peças metálicas que os compõem, e também para que futuramente possam ser desenvolvidas técnicas de proteção e monitoramento cada vez mais eficazes. Dessa forma, será possível reduzir os custos com implantação de novas cadeias de isoladores, manutenção e principalmente com gastos devido aos desligamentos causados por falhas nas peças (GENTIL, 2012).

O presente trabalho tem como objetivos, fazer um estudo morfológico e de corrosão na parte metálica (campânulas e pino) dos isoladores de vidros usados em linhas de transmissão de alta tensão.

\section{METODOLOGIA}

Neste trabalho foram analisadas três amostras de diferentes materiais. A amostra " $\mathrm{A}$ " foi retirada da campânula e a amostra "B" do pino do isolador (Figura 1). Uma terceira amostra "C" de AÇO 304 foi utilizada como referência para posteriores comparações dos resultados. 


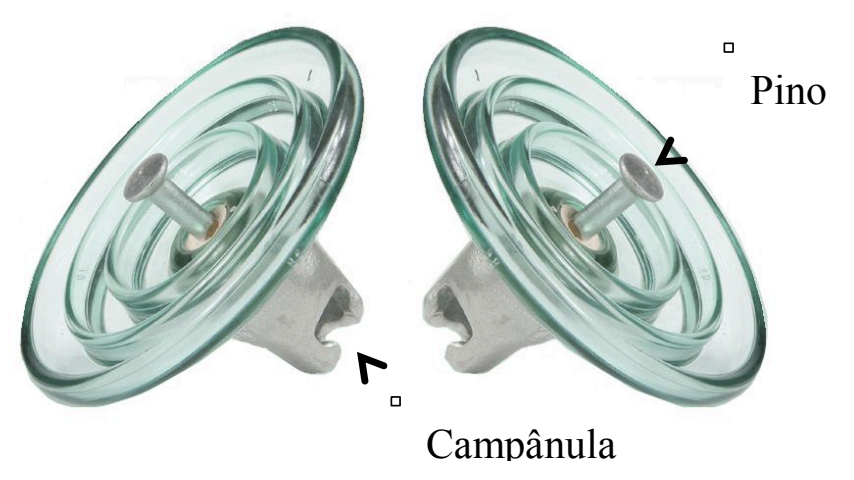

Figura 1 - Amostras retiradas do isolador de vidro.

O aço inoxidável 304 foi utilizado por possuir boas propriedades mecânicas e ser bastante resistente à corrosão, possibilitando assim obter uma relação entre as taxas de corrosão encontradas nas amostras dos isoladores. Os ensaios eletroquímicos deste trabalho foram realizados no Laboratório de Engenharia Eletroquímica - LEEq, da Universidade Federal de Campina Grande - UFCG.

O ensaio metalográfico para avaliar a microestrutura das amostras foi iniciado com o polimento das amostras, a superfície foi submetida a ataque químico com o reagente Nital a $2 \%$. Para avaliação metalográfica, foi utilizado um microscópio Olympus BX 60M com câmera acoplada e software de aquisição e análise de imagens.

Para os ensaios de corrosão, inicialmente quebrou-se o vidro do isolador e fatiou-se amostras da campânula e do pino. Foi feito um polimento das amostras em uma politriz AROTEC - Aropol para remover imperfeições e deixar a superfície das amostras lisas e sem resíduos de óxidos. Após o polimento, soldou-se um fio nas três amostras para possibilitar o acoplamento na célula de corrosão. Realizou-se o isolamento elétrico com uma tinta isolante emborrachada, de modo que apenas uma região conhecida da superfície lisa da amostra ficasse exposta ao ataque corrosivo na célula. Foi feita a limpeza das amostras com álcool etílico e acetona para remover qualquer impureza presente na superfície.

Os ensaios de polarização linear foram conduzidos em uma célula eletroquímica com montagem de três eletrodos, utilizando-se um eletrodo de calomelano como eletrodo de referência, e um contra-eletrodo. O eletrólito utilizado foi uma solução aquosa de $\mathrm{NaCl} 0,2$ $\mathrm{mol} / \mathrm{L}$, agitada por agitador magnético. O sistema foi nitrogenado por 50 minutos para remoção de oxigênio dissolvido do eletrólito, toda a análise foi realizada à temperatura controlada de $30^{\circ} \mathrm{C}$. Todos os eletrodos foram conectados diretamente nos terminais do potenciostato BioLogic modelo SP-150. Através do EC-Lab@Software - Techniques and Applications, version 10.1x, as curvas da análise de polarização linear e as curvas de Taffel foram plotadas. 


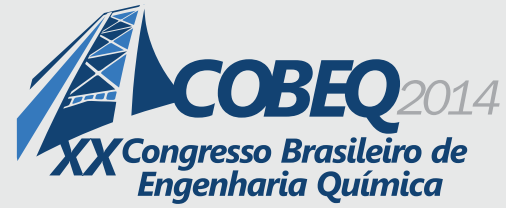

\section{RESULTADOS E DISCUSSÃO}

\subsection{Análise Metalográfica}

A Figura 2 apresenta as micrografias das amostras "A" e "B", campânula e pino, respectivamente, obtidas na análise de metalografia.
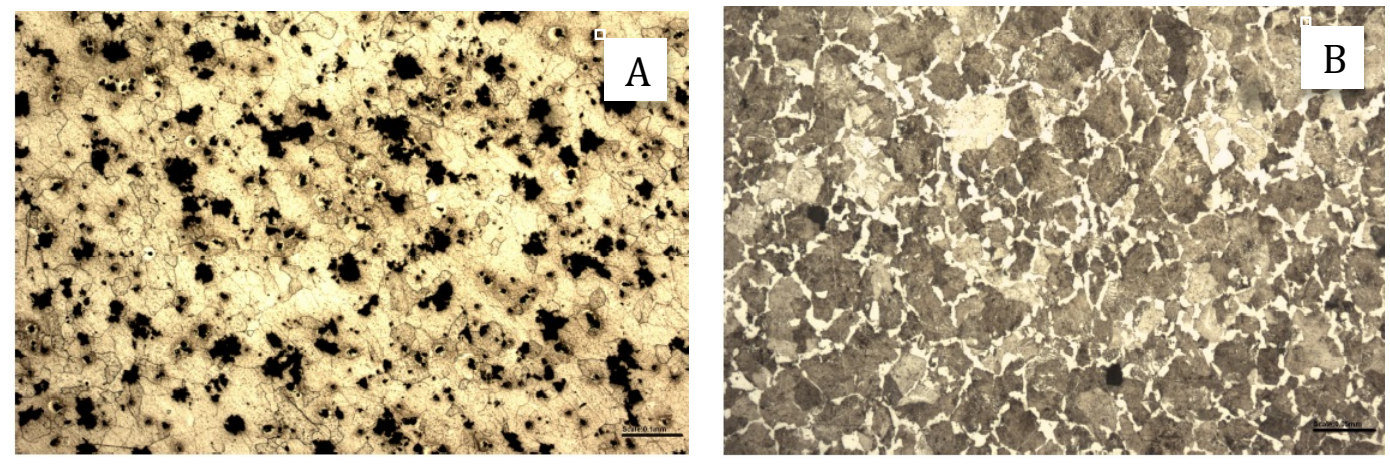

Figura 2 - Metalografia das amostras A e B.

De acordo com a Figura 2, pode-se observar que a micrografia da amostra "A" (campânula) apresenta núcleos de grafita em forma de agregados, que de acordo com Guesser (2009) representa a matriz ferrítica do ferro fundido maleável ferrítico. Já a micrografia da amostra "B" (pino) caracteriza-se pela presença de uma rede de grãos de ferrita, que são os menores e mais claros, e a predominância dos grãos de perlita, que são os mais escuros. Segundo Colpaert (2008), essa granulação é encontrada nos aços com teor de carbono abaixo de $0,8 \%$, que é o caso do aço SAE AISI 1050.

$\mathrm{Na}$ Figura 3 é apresentada uma micrografia do aço tipo ABNT 304 obtida por Santos e Andrade (2008). Observa-se uma microestrutura constituída de grãos austeníticos maclados, isto é, cristalizados. Esta microestrutura permanece no aço não deformado, mesmo após seu resfriamento até a temperatura do nitrogênio líquido.

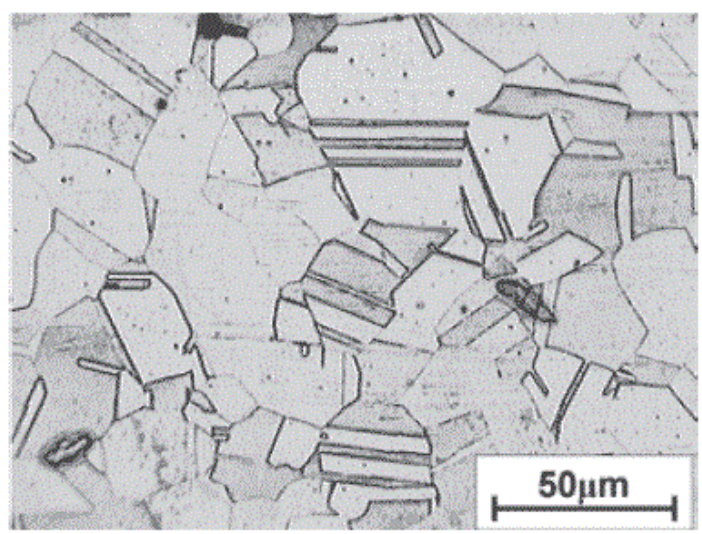

Figura 3 - Metalografia da amostra C. 


\subsection{Ensaio de Polarização Linear}

Os potenciais inicias $\left(\mathrm{E}_{\mathrm{I}}\right)$ e finais $\left(\mathrm{E}_{\mathrm{F}}\right)$ para delimitar a varredura de cada amostra foram calculados a partir do potencial de circuito aberto ( $\left.E_{C A}\right)$, com base na ASTM G59-97(2009) Standart Test Method for Conducting Potentiodynamic Polarization Resistance Measuremments, tendo uma variação de $\pm 30 \mathrm{mV}$. Os valores encontrados estão apresentados na Tabela 1 .

Tabela 1 - Potenciais das amostras "A", "B" e "C".

\begin{tabular}{|c|c|c|c|}
\hline AMOSTRA & $\mathrm{E}_{\mathrm{CA}}(\mathrm{V})$ & $\mathrm{E}_{\mathrm{I}}(\mathrm{V})$ & $\mathrm{E}_{\mathrm{F}}(\mathrm{V})$ \\
\hline A & $-0,720$ & $-0,750$ & $-0,690$ \\
\hline $\mathrm{B}$ & $-0,567$ & $-0,597$ & $-0,537$ \\
\hline $\mathrm{C}$ & $-0,272$ & $-0,302$ & $-0,242$ \\
\hline
\end{tabular}

Para impor experimentalmente a um eletrodo um potencial de eletrodo diferente do de corrosão é preciso lançar mão de fontes externas de potencial como, por exemplo, uma bateria. Neste caso, no entanto, não se consegue manter um controle desse potencial. Um controle adequado do potencial de eletrodo é conseguido com um potenciostato, através do qual é possível, além de impor ao eletrodo o potencial desejado com relação ao eletrodo de referência, também medir a corrente de polarização e, inclusive, registrá-la em função do potencial por meio de um registrador. Pode-se, assim, obter as curvas de polarização experimentais, que representam a relação entre o potencial de eletrodo aplicado e a intensidade de corrente correspondente (WOLYNEC, 2003).

As curvas de polarização estão apresentadas na Figura 4.

Com base no método de extrapolação da curva de Tafel, foram encontradas as constantes anódica $\left(\beta_{\mathrm{a}}\right)$ e catódica $\left(\beta_{\mathrm{c}}\right)$ para cada uma delas. Conhecendo-se estas constantes é possível determinar com mais precisão o valor das correntes e dos potenciais de corrosão de cada amostra e respectiva resistência de polarização $\left(R_{p}\right)$. Os valores obtidos para cada amostra estão apresentados na Tabela 2.

Tabela 2 - Valores obtidos a partir das curvas de polarização das amostras.

\begin{tabular}{|c|c|c|c|c|c|}
\hline Amostra & $\beta_{\mathrm{a}}(\mathrm{mV})$ & $\beta_{\mathrm{c}}(\mathrm{mV})$ & $\mathrm{R}_{\mathrm{p}}(\Omega)$ & $\mathrm{I}_{\mathrm{COR}}(\mu \mathrm{A})$ & $\mathrm{E}_{\mathrm{COR}}(\mathrm{mV})$ \\
\hline $\mathrm{A}$ & 9,0 & 8,8 & 520 & 3,721 & $-733,959$ \\
\hline B & 11,3 & 16,7 & 599 & 4,894 & $-575,315$ \\
\hline C & 12,2 & 11,3 & 13.157 & 0,193 & $-284,92$ \\
\hline
\end{tabular}



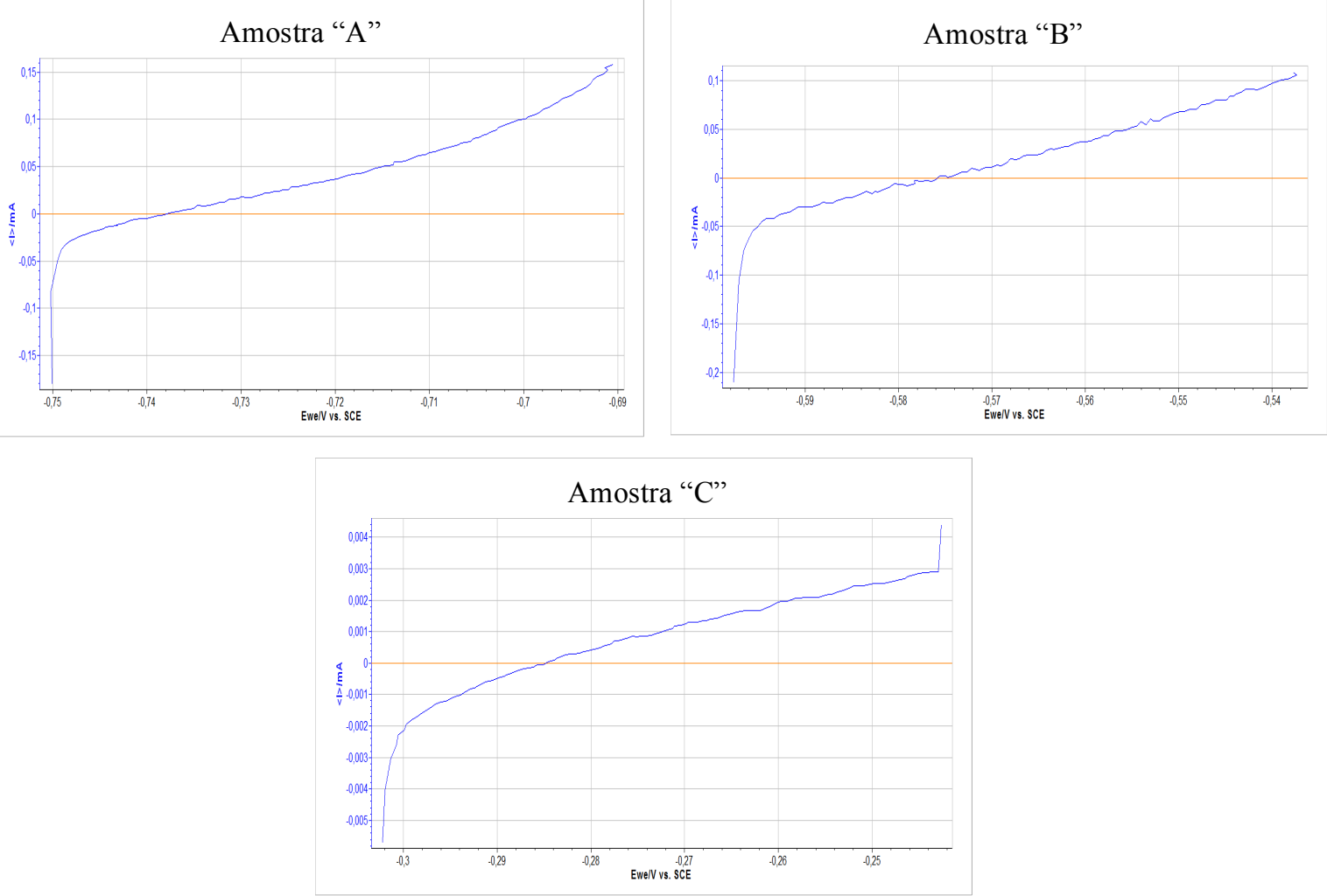

Figura 4 - Curvas de polarização linear das amostras A, B e C.

Em geral, o método clássico e mais simplificado para se determinar a taxa de corrosão é através de medidas de perda de massa, alteração na espessura, identificação dos produtos de corrosão, entre outros. Por outro lado, a determinação da taxa de corrosão por ensaios eletroquímicos, em outras palavras, pela corrosão acelerada, se dá através da obtenção dos seguintes parâmetros: corrente de corrosão $\left(\mathrm{I}_{\text {corr }}\right)$, resistência à polarização $(\mathrm{Rp})$, constantes de Tafel - anódica $\left(\beta_{\mathrm{A}}\right)$ e catódica $\left(\beta_{\mathrm{C}}\right)$ (MORONA, 2007).

A partir dos resultados mostrados na tabela Tabela 2, foi calculado as taxas de corrosão para cada amostra, utilizando-se a equação de Stern-Geary, ASTM G59-97(2009). Na Equação 1, $C R$ é a taxa de corrosão em $\mathrm{mm} / \mathrm{ano}, E W$ é o peso equivalente do metal e $\rho$ é a densidade da liga metálica.

$$
C R=3,27 \cdot 10^{-3}\left(\frac{I_{c o r} \cdot E W}{\rho}\right)
$$

Os resultados da taxa de corrosão $(C R)$, os valores de peso equivalente $(E W)$ e densidade $(\rho)$ de cada amostra estão apresentados na Tabela 3. 
Tabela 3 - Resultados obtidos para as amostras A, B e C.

\begin{tabular}{|c|c|c|c|}
\hline Amostra & $\rho\left(\mathrm{g} / \mathrm{cm}^{3}\right)$ & $E W(\mathrm{~g} / \mathrm{mol})$ & $C R(\mathrm{~mm} / \mathrm{ano})$ \\
\hline $\mathrm{A}$ & 7,6684 & 20,4559 & 0,03244 \\
\hline $\mathrm{B}$ & 7,4765 & 26,5845 & 0,05696 \\
\hline $\mathrm{C}$ & 6,7268 & 24,3130 & 0,00228 \\
\hline
\end{tabular}

Os resultados encontrados mostram que das três amostras analisadas pelo processo de corrosão, a amostra "B", que compõe o pino do isolador e a amostra "A" da campânula, apresentaram valores de taxa de corrosão relativamente próximas devido a natureza ferrítica desses materiais, no entanto a presença de perlita na amostra B confere uma taxa de corrosão um pouco mais elevada na ordem de duas vezes superior. A amostra "C", aço 304, serve apenas como parâmetro de referência.

Com a finalidade de comparar os resultados encontrados para cada amostra, as três curvas de Tafel são apresentadas na Figura 5, nota-se o deslocamento crescente do potencial de corrosão.

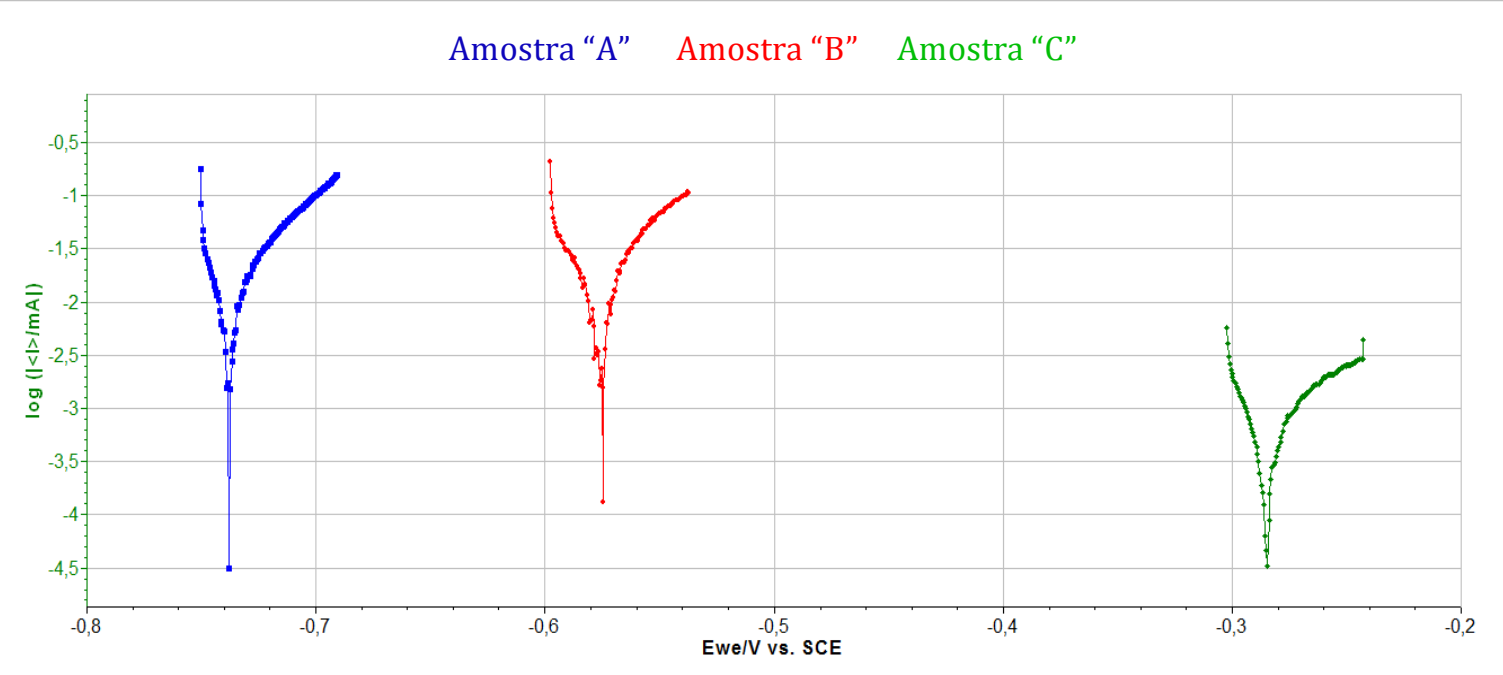

Figura 5 - Curvas de Tafel e potenciais de corrosão para as amostras A, B e C.

A partir da Figura 5 é possível confirmar que o aço austenítico 304 tomado aqui como referência é o material menos afetado pelo processo corrosivo, tendo em vista que ele apresenta o maior (menos negativo) potencial de corrosão e a menor corrente de corrosão das três amostras analisadas. Tal fato indica uma maior estabilidade na camada de passivação do aço em ambientes com cloreto, que pode ser justificada pelo elevado percentual de cromo presente em sua composição, estando esse resultado de acordo com Silva e Mei (2010). 


\section{CONCLUSÃO}

Os resultados apresentados e as discussões pertinentes conduziram às seguintes conclusões:

- Percebeu-se que a liga de aço-carbono que constitui o pino do isolador de vidro estudado é a mais afetada pelo processo corrosivo.

- Com relação à amostra de aço 304, tomado aqui como referência, foi possível verificar sua propriedade de resistência à corrosão, característica de uma liga com elevado teor de cromo, que lhe confere uma camada de passivação.

- De forma geral, os resultados mostram que as ligas metálicas que compõem o isolador estudado não são atacadas corrosivamente com facilidade, devido a formação de camadas passivas durante sua vida útil, mostrando que estas possuem ainda uma boa resistência à corrosão e ainda sendo competitiva para construção de isoladores do ponto de vista custo/benefício.

\section{REFERENCIAS}

GENTIL, Vicente. Corrosão. 6. ed. Rio de Janeiro: LTC, 2012. 360 p.

GUESSER, Wilson Luiz. Propriedades Mecânicas dos Ferros Fundidos. São Paulo: Blucher, 2009. 336 p.

MORONA, Marcelo Tadeu. Ensaios eletroquímicos e influência da nitretação à plasma na resistência à corrosão do aço inoxidável ISO 5832-1. 2007. 94 f. Dissertação (Mestrado), Universidade Tecnológica Federal do Paraná, Curitiba, 2007.

SANTOS, T. F. A.; ANDRADE, M. S. Avaliação dilatométrica da reversão das martensitas induzidas por deformação em um aço inoxidável austenítico do tipo ABNT 304. Revista Matéria, Belo Horizonte, v. 13, n. 4, p.587-596, 2008.

SILVA, André Luiz V. da Costa e; MEI, Paulo Roberto. Aços e Ligas Especiais. 3. ed. São Paulo: Blucher, 2010. 646 p.

WOLYNEC, Stephan. Técnicas Eletroquímicas em Corrosão. São Paulo: Edusp, 2003. 176 p.

YANAGUIZAWA, Juliana de Almeida; SHINOHARA, Armando Hideki. Isolamento mínimo em cadeias de isoladores de vidro danificados por vandalismo em linhas de transmissão. Revista de Ciência, Tecnologia e Humanidades do Ifpe, Recife, v. 3, n. 1, p.132-142, jul. 2011. 